\title{
Non-enzymatic Glucose Sensor Based on CuO Nanoplates
}

\author{
Chu Thi Xuan \\ Hanoi University of Science and Technology, No. 1, Dai Co Viet str., Hai Ba Trung dist., Hanoi, Viet Nam \\ Received: April 10, 2020; Accepted: November 12, 2020
}

\begin{abstract}
We have successfully fabricated an electrochemical sensor for non-enzymatic glucose measurement based on copper oxide (CuO) nanoplates. CuO nanoplates were synthesized by a facile hydrothermal method at $180{ }^{\circ} \mathrm{C}$ for $23 \mathrm{~h}$ without using any surfactants. Filed-emission scanning electron microscopy (FE-SEM) and $X$-ray diffraction (XRD) were used to characterize morphologies and crystal structures of synthesized CuO nanoplates. A mixture of $\mathrm{CuO}$ nanoplates and polytetrafluoroethylene with mass ratio 0.15:1 was compressed at $9800 \mathrm{kPa}$ onto platinum (Pt) to form Pt/CuO disk and it has been used as a working electrode for glucose measurement following non-enzymatic approach. Glucose concentration was evaluated by cyclic voltammetry in $0.1 \mathrm{M} \mathrm{NaOH}$ solution. This enzyme-free electrochemical method was able to detect glucose with a concentration as low as $0.1 \mathrm{mM}$. These results show that CuO nanoplates are a promising candidate for non-enzymatic glucose detection.
\end{abstract}

Keywords: non-enzymatic glucose detection, CuO nanoplates, electrochemical method

\section{Introduction}

Diabetes mellitus is a type of metabolic disorders characterized by a high blood sugar level resulting from the dysfunction of insulin secretion. Long-term diabetes may cause multiple complications such as blindness, cardiovascular disorders, and kidney failure [1]. Therefore, it is a critical need to control and monitor the blood glucose level. For this reason, glucose sensors have been extensively researched and developed, especially for diabetes diagnosis [2].

Enzymatic glucose sensors have been extensively developed because of their broad applications in the food industry, biotechnology, clinical diagnostics, particularly in self-testing and continuous blood glucose monitoring [3]. The presence of glucose is detected by measuring the rate of glucose oxidation from the enzyme glucose oxidase. Electrochemical enzymatic glucose sensors have attracted great attention from researchers because of excellent selectivity and high reliability [2]. However, these sensors have some disadvantages such as naturally insufficient stability, loss of enzyme activity during the immobilization process [4], constraint on $\mathrm{pH}$ of $2-8$, temperatures below $44^{\circ} \mathrm{C}$, and ambient humidity levels [5]. Considering these disadvantages of the enzyme, non-enzymatic glucose sensors have attracted increasing research attention thank to their low cost, high stability, prompt

*Corresponding author: Tel.: (+84) 333620899

Email: xuan.chuthi@hust.edu.vn;

xuan@itims.edu.vn response, and low detection limit [2]. The fabrication of a wide variety of nanomaterials such as metals, metal oxides has introduced plenty of selective and highly responsive glucose sensors.

Among metal oxide materials, $\mathrm{CuO}$ nanostructures are widely studied materials and have been used to detect glucose [6] because of its electrochemical activity which promotes electrontransfer reactions even at a lower overpotential [7]. $\mathrm{CuO}$ nanostructures with different structures such as nanoparticles [8], nano bricks [7], nanoseeds [9][10], nanowires [11] have been used to measure glucose concentration with the limit of detection in the order of $\mu \mathrm{mol} / \mathrm{L}$. The modification of $\mathrm{CuO}$ nanostructures with other materials such as carbon nanotubes [12], graphene [13], $\mathrm{ZnO}$ nanorods [14] exhibits enhanced electrochemical properties and also enhanced glucose detection. However, the number of studies on the use of $\mathrm{CuO}$ nanostructures applied to the detection of biological objects is still limited. Furthermore, there are no studies related to the fabrication and use of $\mathrm{CuO}$ nanoplates for biosensor applications.

In this work, $\mathrm{CuO}$ nanoplates were prepared by a surfactant-free hydrothermal method. Then, $\mathrm{CuO}$ nanoplates have been used to modify Pt disk for the development of a non-enzymatic electrochemical glucose sensor. The prepared $\mathrm{Pt} / \mathrm{CuO}$ sensor showed sensitivity in alkaline media for electrochemical glucose sensing, which is promising to be an excellent non-enzymatic glucose sensor. 


\section{Experiments}

\subsection{Hydrothermal synthesis of $\mathrm{CuO}$ nanoplates}

$\mathrm{CuO}$ nanoplates were synthesized by a simple hydrothemal method without using any surfactant. In a typical process, $2.4 \mathrm{~g} \mathrm{CuCl}_{2}$ and $1.7 \mathrm{~g} \mathrm{KOH}$ were dissolved in $80 \mathrm{~mL}$ of deionized water (DI) using a magnetic stirring for about $20 \mathrm{~min}$ at room temperature. The mixed solution was transferred into a Teflon-lined autoclave (100 $\mathrm{mL}$ in volume) for hydrothermal treatment at $180{ }^{\circ} \mathrm{C}$ for $23 \mathrm{~h}$. The resulted products were washed five times with DI water and collected with ethanol solution by centrifugation at $4000 \mathrm{rpm}$ for $15 \mathrm{~min}$. Finally, the collected products were dried at $60{ }^{\circ} \mathrm{C}$ for $20 \mathrm{~h}$. The morphologies and crystal structures of the assynthesized materials were characterized by fieldemission scanning electron microscopy (FESEM, JEOL 7600F) and power X-ray diffraction (XRD; Advance D8, Bruker) respectively.

\subsection{Fabrication of $\mathrm{CuO}$ nanoplates modified Pt grid}

In a typical process, $0.14 \mathrm{~g} \mathrm{CuO}$ was mixed with $0.02 \mathrm{~g}$ polytetrafluoroethylene (PTFE) and crushed in an agate mortar. The mixed composition was compressed under a pressure of $9800 \mathrm{kPa}$ to form a round disk of $1 \mathrm{~cm}$ in diameter. The $\mathrm{CuO}$ nanoplates modified Pt grid was obtained by compressing the round disk to a Pt grid.

\subsection{Non-enzymatic glucose measurement with the electrochemical method}

The glucose measurement was performed at room temperature by using the PGSTAT30 Autolab electrochemical workstation (Eco Chemie, Netherlands). Three electrodes were used: reference electrode $(\mathrm{Ag} / \mathrm{AgCl}$, Metrohm), counter electrode $(\mathrm{Pt})$, and the working electrode $(\mathrm{Pt} / \mathrm{CuO}$ nanoplates). Cyclic voltammograms (CV) were performed in $\mathrm{NaOH} 0.1 \mathrm{M}$ with potential from -0.6 to $0.8 \mathrm{~V}$ until reproducible background voltammograms were obtained. Non-enzymatic glucose measurement was carried out in $0.1 \mathrm{M} \mathrm{NaOH}$ at the potential from 0 to $0.7 \mathrm{~V}$ at a scan rate of $50 \mathrm{mV} / \mathrm{s}$.

\section{Results and discussion}

\subsection{Characterization of $\mathrm{CuO}$ nanoplates}

Fig.1 shows the FE-SEM images of $\mathrm{CuO}$ nanostructures synthesized using the hydrothermal method. As shown in Fig.1, nanoplates were formed with the width, length, and thickness of $0.9 \pm 0.08 \mu \mathrm{m}, 1.76 \pm 0.15 \mu \mathrm{m}$, and $70 \pm 4 \mathrm{~nm}$ respectively.

The XRD pattern of the fabricated $\mathrm{CuO}$ nanoplates is shown in Fig.2. All typical diffraction peaks can be readily indexed to the monoclinic structure of $\mathrm{CuO}$ (JCPDS PDF card No. 05-0611). The major peaks located at $2 \theta=35.5^{\circ}$ and $38.7^{\circ}$ are indexed as (002) and (111) crystal planes, respectively. Except for $\mathrm{CuO}$, no other peaks were observed in the pattern, which verified that the synthesized nanostructures were pure $\mathrm{CuO}$.

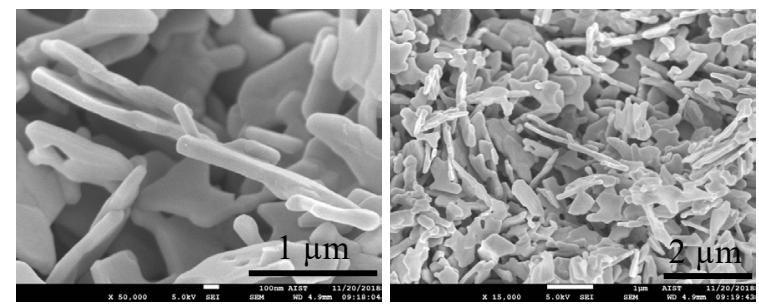

Fig. 1. FE-SEM images of $\mathrm{CuO}$ nanostructures were synthesized by the hydrothermal method at $180{ }^{\circ} \mathrm{C}$ for $23 \mathrm{~h}$.

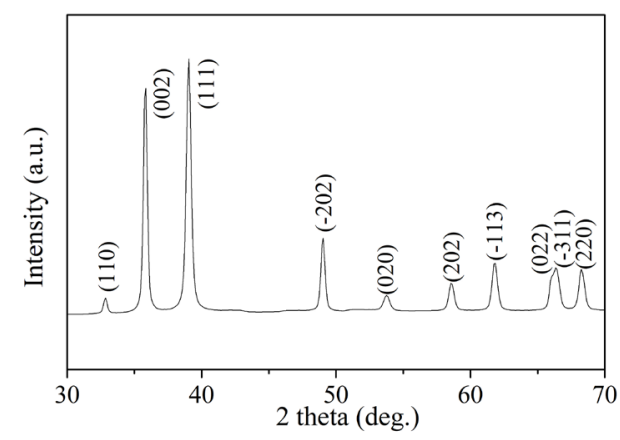

Fig. 2. X-ray diffraction patterns of $\mathrm{CuO}$ nanomaterials fabricated by hydrothermal synthesis at $180^{\circ} \mathrm{C}$ for $23 \mathrm{~h}$.

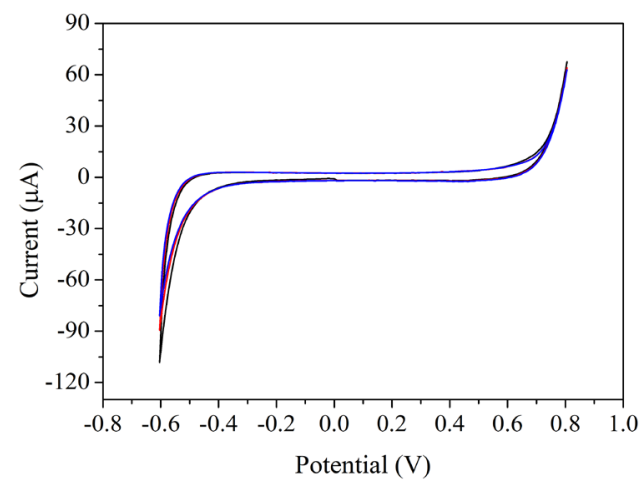

Fig. 3. $\mathrm{CV}$ of $\mathrm{Pt}$ working electrode in $\mathrm{NaOH} 0.1 \mathrm{M}$ with potential from -0.6 to $0.8 \mathrm{~V}$ at a scan rate of $50 \mathrm{mV} / \mathrm{s}$

\subsection{Glucose measurement using cyclic voltammetry}

Before glucose measurement, cyclic voltammograms $(\mathrm{CV})$ of $\mathrm{Pt}$ working electrode were performed in $\mathrm{NaOH} 0.1 \mathrm{M}$ with potential from -0.6 to $0.8 \mathrm{~V}$ until reproducible background voltammograms were obtained (Fig.3). As shown in Fig.3, hydrogen evolution and oxidation reactions started at -0.4 and 
$0.7 \mathrm{~V}$ respectively. The windown potential in this experiment is from $-0.4 \mathrm{~V}$ to $0.7 \mathrm{~V}$. In the current experiments, we aim to detect glucose oxidation reaction, the potential range from 0 to $0.7 \mathrm{~V}$ was selected for further experiments.

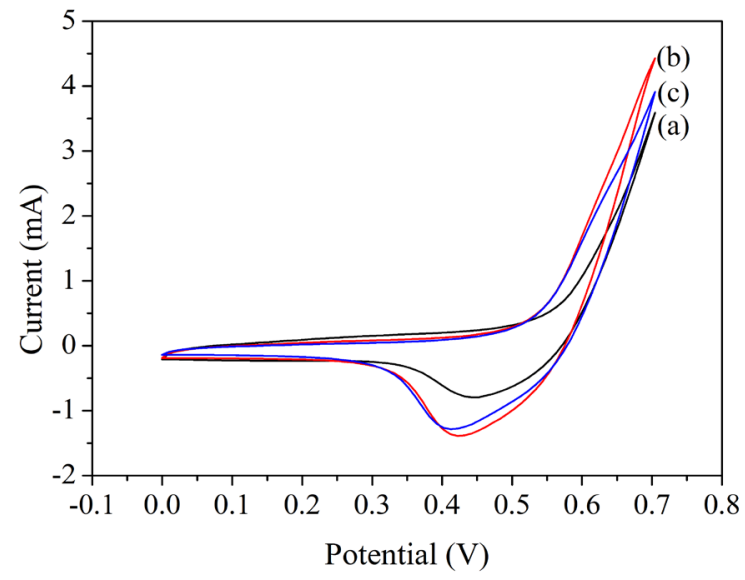

Fig. 4. $\mathrm{CV}$ of $\mathrm{CuO}$ nanoplates in $\mathrm{NaOH} 0.1 \mathrm{M}$ in the presence of (a) $0 \mathrm{M}$ glucose, (b) $0.1 \mathrm{mM}$ glucose, and (c) $2 \mathrm{mM}$ glucose at a scan rate of $50 \mathrm{mV} / \mathrm{s}$.

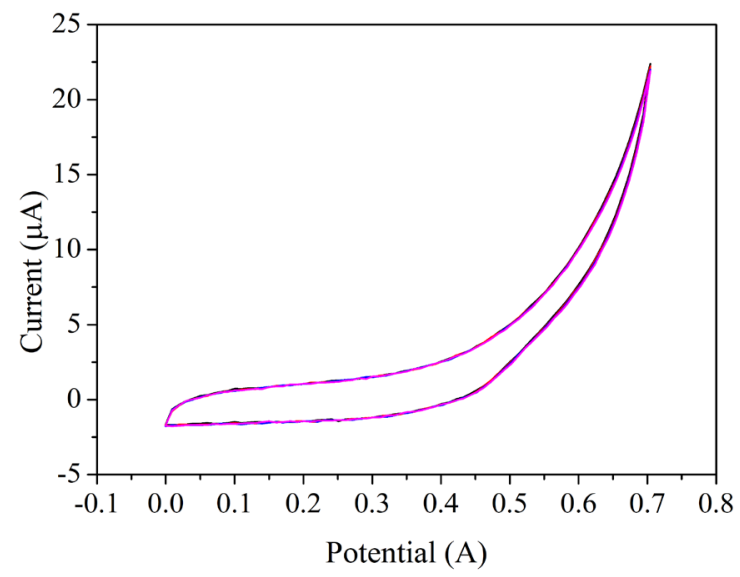

Fig. 5. $\mathrm{CV}$ of $\mathrm{Pt}$ electrode in $\mathrm{NaOH} 0.1 \mathrm{M}$ in the presence of $2 \mathrm{mM}$ glucose.

The cyclic voltammetry was applied to the $\mathrm{Pt} / \mathrm{CuO}$ nanoplates electrode to measure glucose concentration in $\mathrm{NaOH} 0.1 \mathrm{M}$ at $50 \mathrm{mV} / \mathrm{s}$ (Fig.4). As shown in Fig.4a, when glucose was not added to the electrolyte solution, no oxidation peak was observed. When $0.1 \mathrm{mM}$ glucose was added to the electrolyte solution, the oxidation peak at $0.65 \mathrm{~V}$ was found (Fig.4b). The oxidation peak was clearer when glucose concentration was increased to $2 \mathrm{mM}$ (Fig.4c). Similar results were found in the research of Rahim et al. [15] when measuring glucose with $\mathrm{SiO}_{2} / \mathrm{C} / \mathrm{CuO}$ working electrode.

In order to verify the role of $\mathrm{CuO}$ nanostructures in glucose oxidation, the cyclic voltammogram was performed with $\mathrm{Pt}$ electrode in $\mathrm{NaOH} 0.1 \mathrm{M}$ in the presence of $2 \mathrm{mM}$ glucose. As shown in Fig.5, no glucose oxidation peak was observed. This result confirms the role of $\mathrm{CuO}$ nanostructures as electrocatalytic oxidation of glucose in an alkaline medium. The double bond between the copper and oxygen atoms facilitates the electron transfer from the electrode surface to glucose [13].

The mechanism for electrocatalytic oxidation of glucose by $\mathrm{CuO}$ nanostructures can be divided into three steps as shown in Scheme 1 [4][13]. In the first step, the $\mathrm{CuO}$ is electrochemically oxidized to strong oxidizing agent $\mathrm{Cu}^{3+}$ species when it is diffused to the electrode surface (Equation 1). The $\mathrm{Cu}^{3+}$ oxidizes glucose to form gluconolactone in the second step (Equation 2), which can be easily transformed into gluconic acid in an aqueous medium in the third step (Equation 3).

$\mathrm{Cu}^{2+}+\mathrm{OH}^{-} \rightarrow \mathrm{Cu}^{3+}+\mathrm{e}-$

$\mathrm{Cu}^{3+}+$ glucose + e- $\rightarrow$ gluconolactone $+\mathrm{Cu}^{2+}$

Gluconolactone $\rightarrow$ gluconic acid

Scheme 1. The mechanism for electrocatalytic oxidation of glucose by $\mathrm{CuO}$ nanostructures.

$\mathrm{CuO}$ nanoplates fabricated with the hydrothermal method can be used to detect glucose with concentration as low as $0.1 \mathrm{mM}$ by electrochemical method. This value is much smaller than the allowed blood glucose level (3.8 to $5.1 \mathrm{mM}$ ). However, the response signal is still quite small as compared to previous research based on electrochemical detection of glucose on different $\mathrm{CuO}$ nanostructures [7][10]. Functionalization of $\mathrm{CuO}$ nanoplates by some materials such as carbon nanotube, graphene, or other metals may help to increase the sensitivity of the sensor.

\section{Conclusion}

$\mathrm{CuO}$ nanoplates have been successfully fabricated using the simple hydrothermal method at $180{ }^{\circ} \mathrm{C}$ for $23 \mathrm{~h}$ without using any surfactant. The asfabricated $\mathrm{CuO}$ nanoplates were mixed with PTFE and compressed to $\mathrm{Pt}$ grid to form $\mathrm{Pt} / \mathrm{CuO}$ nanoplates working electrode for electrochemical experiments. Cyclic voltammetry was performed on the $\mathrm{Pt} / \mathrm{CuO}$ nanoplates electrode with potential from 0 to $0.7 \mathrm{~V}$ in $\mathrm{NaOH} 0.1 \mathrm{M}$ to detect glucose. The oxidation peak of glucose was found at $0.65 \mathrm{~V}$ with a concentration as low as $0.1 \mathrm{mM}$. The role of $\mathrm{CuO}$ nanostructures as electrocatalytic oxidation of glucose in alkaline medium was verified. The results show that $\mathrm{CuO}$ nanoplates are promising materials for glucose detection. The functionalization of $\mathrm{CuO}$ nanoplates may improve the sensitivity of the glucose sensor. 


\section{Acknowledgments}

This research is funded by the Hanoi University of Science and Technology (HUST) under project number T2018-PC-220.

\section{References}

[1] H. Lee, Y. J. Hong, S. Baik, T. Hyeon, and D. H. Kim, Enzyme-Based Glucose Sensor: From Invasive to Wearable Device, Adv. Healthc. Mater., vol. 7, no. 8, (2018), pp. 1-14.

[2] H. Zhu, L. Li, W. Zhou, Z. Shao, and X. Chen, Advances in non-enzymatic glucose sensors based on metal oxides, J. Mater. Chem. B, vol. 4, no. 46, (2016), pp. 7333-7349.

[3] K. E. Toghill and R. G. Compton, Electrochemical non-enzymatic glucose sensors: A perspective and an evaluation, Int. J. Electrochem. Sci., vol. 5, no. 9, (2010), pp. 1246-1301.

[4] A. Safavi, N. Maleki, and E. Farjami, Fabrication of a glucose sensor based on a novel nanocomposite electrode, Biosens. Bioelectron., vol. 24, no. 6, (2009), pp. 1655-1660.

[5] R. Wilson and A. P. F. Turner, Glucose oxidase: an ideal enzyme, Biosens. Bioelectron., vol. 7, no. 3, (1992), pp. 165-185.

[6] X. Wang, C. Hu, H. Liu, G. Du, X. He, and Y. Xi, Synthesis of $\mathrm{CuO}$ nanostructures and their application for nonenzymatic glucose sensing, Sensors Actuators B Chem., vol. 144, no. 1, (2010), pp. 220-225.

[7] S. A. Khayyat, S. G. Ansari, and A. Umar, Glucose sensor based on copper oxide nanostructures, J. Nanosci. Nanotechnol., vol. 14, no. 5, (2014), pp. 3569-3574.

[8] A. Ashok, A. Kumar, and F. Tarlochan, Highly efficient nonenzymatic glucose sensors based on
$\mathrm{CuO}$ nanoparticles, Appl. Surf. Sci., vol. 481, (2019) pp. 712-722.

[9] R. Ahmad, N. Tripathy, Y.-B. Hahn, A. Umar, A. A. Ibrahim, and S. H. Kim, A robust enzymeless glucose sensor based on $\mathrm{CuO}$ nanoseed modified electrodes, Dalt. Trans., vol. 44, no. 28, (2015), pp. 1248812492.

[10] Z. H. Ibupoto, K. Khun, V. Beni, X. Liu, and M. Willander, Synthesis of novel $\mathrm{CuO}$ nanosheets and their non-enzymatic glucose sensing applications, Sensors (Switzerland), vol. 13, no. 6, (2013), pp. 7926-7938.

[11] Z. Zhuang, X. Su, H. Yuan, Q. Sun, D. Xiao, and M. M. F. Choi, An improved sensitivity non-enzymatic glucose sensor based on a $\mathrm{CuO}$ nanowire modified $\mathrm{Cu}$ electrode, Analyst, vol. 133, no. 1, (2008), pp. 126-132.

[12] X. Zhang, G. Wang, W. Zhang, Y. Wei, and B. Fang, Fixure-reduce method for the synthesis of $\mathrm{Cu}$ 2O/MWCNTs nanocomposites and its application as enzyme-free glucose sensor, Biosens. Bioelectron., vol. 24, no. 11, (2009), pp. 3395-3398.

[13] S. Muralikrishna, K. Sureshkumar, Z. Yan, C. Fernandez, and T. Ramakrishnappa, Non-enzymatic amperometric determination of glucose by $\mathrm{CuO}$ nanobelt graphene composite modified glassy carbon electrode, J. Braz. Chem. Soc., vol. 26, no. 8, (2015), pp. 1632-1641.

[14] R. Ahmad et al., Highly Efficient Non-Enzymatic Glucose Sensor Based on CuO Modified VerticallyGrown ZnO Nanorods on Electrode, Sci. Rep., vol. 7, no. 1, (2017), p. 5715.

[15] A. Rahim et al., A non-enzymatic glucose sensor based on CuO-nanostructure modified carbon ceramic electrode, J. Mol. Liq., vol. 248, (2017), pp. 425-431. 